\title{
High-Dose Melphalan and Autologous Peripheral Blood Stem Cell Transplantation in AL Amyloidosis
}

\author{
Vaishali Sanchorawala \\ Amyloidosis Center, Boston University School of Medicine and Stem Cell Transplantation Program of Section of \\ Hematology and Oncology, Boston Medical Center, Boston, MA, USA
}

\section{Keywords}

AL amyloidosis · Stem cell transplantation · Melphalan .

Treatment-related mortality · Patient selection

\begin{abstract}
AL amyloidosis is a systemic amyloidosis and is associated with an underlying plasma cell dyscrasia. High-dose intravenous melphalan and autologous stem cell transplantation was developed for the treatment of AL amyloidosis in the early 1990s and was prompted by its success in myeloma. This application has evolved significantly over the past three decades. This review provides a comprehensive assessment of eligibility criteria, stem cell collection, and mobilization strategies and regimens, risk-adapted melphalan dosing, role for induction and consolidation therapies as well as long-term outcome with respect to survival, hematologic response and relapse as well as organ responses following stem cell transplantation. Continued efforts to refine patient selection and management, and incorporate novel antiplasma cell agents in combination or sequentially to further improve outcomes in AL amyloidosis are also discussed.
\end{abstract}

(c) 2020 S. Karger AG, Basel

karger@karger.com

www.karger.com/aha

(c) 2020 S. Karger AG, Base

Karger!

\section{Introduction}

Immunoglobulin light-chain (AL) amyloidosis is the most common form of systemic amyloidosis in the US and Europe. Clonal plasma cells in the bone marrow produce an amyloidogenic light chain which misfolds to form soluble aggregates and oligomers which interact with serum amyloid $\mathrm{P}$ protein and glycosaminoglycans to form amyloid fibril deposits [1]. The mechanisms of clinical disease are related to either disruption of the architecture of the affected organs due to amyloid deposits and/or direct cytotoxicity of the soluble precursor protein [2].

\section{Treatment Targets}

A detailed elaboration of the pathogenesis of AL amyloidosis is beyond the scope of this paper. However, each of the steps in the pathogenesis of amyloidosis, from the production of the precursor protein to formation of amyloid deposits, is a potential target for treatment. Preclinical and clinical studies are being designed or are ongoing for several of these targets. Reducing the

Vaishali Sanchorawal

Amyloidosis Center, Boston Medical Center

820 Harrison Avenue, FGH 1007

Boston, MA 02118 (USA)

vaishali.sanchorawala@bmc.org 
amyloidogenic precursor protein, i.e., light chains produced by the clonal plasma cell dyscrasia, with chemotherapeutic agents has been used for the past several decades.

\section{Treatment: General Principles}

The two keys to effective treatment of AL amyloidosis are early diagnosis and correct typing. Ideally, treatment should be started before irreversible organ damage has occurred. Once the diagnosis of AL amyloidosis has been firmly established, the design of the therapeutic strategy depends on a fine balance between the efficacy of the chosen regimen and the individual patient's expected ability to tolerate the toxicity of the treatment regimen, especially in the setting of cardiac involvement with amyloidosis. The current therapeutic approach to systemic AL amyloidosis is based upon the observation that organ function restores if the synthesis of the amyloidogenic protein precursor is shut down. Therefore, the aim of therapy in AL amyloidosis is to rapidly reduce the supply of misfolded amyloid-forming monoclonal free light chains by suppressing the underlying plasma cell dyscrasia while using supportive measures to preserve target organ functions.

\section{Monitoring the Therapeutic Effect}

The criteria for hematologic and organ responses have been unified, formalized, and recently updated by the International Symposium on Amyloidosis [3, 4]. Hematologic response usually translates into clinically improved organ function and is associated with a substantial survival advantage and improved quality of life. However, if the organ damage is advanced, it may be irreversible despite hematologic response. Most patients with a hematologic response show a clinical response after 3-6 months, although late responses have been observed [5].

\section{Initial Pilot Studies of High-Dose Chemotherapy and Stem Cell Transplantation in AL Amyloidosis}

High-dose intravenous melphalan chemotherapy and autologous peripheral blood stem cell transplantation (SCT) has been successful in inducing complete hematologic remissions and prolonging survival in multiple my- eloma $[6,7]$. Therefore, it was logical to apply this approach to the treatment of AL amyloidosis. The Amyloid Research and Treatment Program, now called Amyloidosis Center, at Boston University School of Medicine has a long-standing investigative interest in the pathophysiology and treatment of the various forms of systemic amyloidoses. In 1994, a multidisciplinary clinical group was formed to develop high-dose chemotherapy protocols for AL amyloidosis. This group was made up of clinicians allied with the Amyloid Research and Treatment Program, representing the disciplines of cardiology, nephrology, pulmonology, neurology, gastroenterology, and rheumatology, together with hematologists in the Stem Cell Transplant Program of the Section of Hematology and Oncology and clinical pathologists from the Transfusion Medicine and Blood Bank.

In 1996, we reported our initial experience with highdose melphalan and SCT (HDM/SCT) in 5 patients with AL amyloidosis [8]. This pilot study showed that AL amyloidosis patients with significant systemic disease could be successfully treated with HDM/SCT. Furthermore, 3 of the 5 patients achieved a hematologic complete response (CR), with disappearance of their underlying clonal plasma cell disorder following treatment. Moreover, all 5 patients experienced reversal of amyloid-related organ dysfunction.

\section{Cumulative Experience of HDM/SCT at a Single Center}

An expanded series of 312 patients was reported from our group in 2004 [9]. Hematologic CR occurred in $40 \%$ of evaluable patients and $66 \%$ of the patients achieved improvement in at least one organ function with a hematologic CR. Moreover, the median survival was 4.6 years for this cohort. This study was updated in 421 patients in 2011 reporting a median event-free survival of 2.6 years and median overall survival (OS) of 6.3 years [10].

Most recently, the long-term outcome of $629 \mathrm{pa}-$ tients with $\mathrm{AL}$ amyloidosis undergoing HDM/SCT from 1994 to 2014 has been analyzed [11]. Treatmentrelated mortality (TRM) defined as death occurring within 100 days after SCT occurred in 47 patients, leading to an overall TRM of $7.5 \%$. Additionally, there were 11 deaths during stem cell mobilization and collection phase prior to initiating HDM. After 2005, no deaths have occurred during stem cell mobilization and collection, and TRM has improved to $3.4 \%$. Hematologic CR 
was achieved by $35 \%$ by an intention-to-treat analysis and $40 \%$ in evaluable patients. Hematologic CR was $45 \%$ for those who received $200 \mathrm{mg} / \mathrm{m}^{2}$ of melphalan compared to $34 \%$ for those who received $100-140 \mathrm{mg} /$ $\mathrm{m}^{2}$ of melphalan $(p=0.009)$. The median OS was 7.6 years. The median OS was significantly better for those who achieved a hematologic CR, for those without cardiac involvement and for those with $<2$ organ system involvement. Hematologic relapses occurred in $18 \%$ of patients with hematologic CR at a median of 4 years (range 1.8-12.5) [11]. Long-term survival of $>20$ years occurred in $30 \%$ of patients.

\section{Eligibility Criteria for HDM/SCT}

The eligibility criteria for HDM/SCT have varied from center to center. However, only $20-30 \%$ of newly diagnosed patients are eligible to receive this aggressive form of treatment. Eligibility criteria for treatment with HDM/SCT at our institution are quite liberal and have required a confirmed tissue diagnosis of amyloidosis, clear evidence of a clonal plasma cell dyscrasia, age $>18$ years, and minimum measures of performance status (SWOG 0-2), cardiac function (LVEF $>40 \%$ ), pulmonary function $\left(\mathrm{O}_{2}\right.$ saturation $>95 \%$ on room air $)$, and hemodynamic stability (baseline systolic blood pressure $>90 \mathrm{~mm} \mathrm{Hg}$ ). Patients on hemodialysis or peritoneal dialysis for renal failure are not excluded if other eligibility criteria are met. Cardiac biomarker staging system can also define risk of treatment-related complications while undergoing HDM/SCT. Elevated cardiac troponin T levels and NTproBNP levels of $>5,000 \mathrm{pg} /$ $\mathrm{mL}$ are associated with poor survival while undergoing $\mathrm{HDM} / \mathrm{SCT}[12]$.

\section{Induction Regimens, Choice, and Duration}

As the burden of clonal plasma cells is modest in most patients with $\mathrm{AL}$ amyloidosis, induction with a cytoreducing regimen prior to HDM/SCT, as is done in multiple myeloma, seems unnecessary although possible benefits of induction treatment before SCT have been reported. Evidence from a randomized clinical trial indicates that the delay associated with pretransplant cytoreduction, using oral melphalan and prednisone (MP), can allow disease progression and can lead to survival disadvantage in patients with cardiac involvement [13]. However, this trial was critiqued for the use of non-con- temporary induction regimen. Induction therapy with novel agents prior to HDM/SCT, specifically bortezomib and dexamethasone, has been studied in multiple clinical trials showing higher hematologic response rates, organ responses, and OS [14-16]. Nevertheless, induction therapy should be used with caution of not delaying more definitive treatment, as $14-35 \%$ of patients would not proceed to SCT after induction due to clinical deterioration of organ function making them ineligible to undergo SCT. Currently, the use of induction therapy is utilized in patients with $>10 \%$ plasma cells in the bone marrow at diagnosis because of the impact of this level of plasmacytosis on OS [17]. However, this remains controversial due to conflicting reports from our group [18] as well as the issue of clinical deterioration during induction therapy.

\section{Stem Cell Mobilization and Collection}

Previous exposure to alkylating agents impairs hematopoietic stem cell collection. A total dose of oral melphalan exceeding $200 \mathrm{mg}$ may significantly reduce the ability to mobilize CD34+ cells. Contrary to the common experience in multiple myeloma, deaths have been reported during mobilization and leukapheresis of patients with AL amyloidosis who have cardiac or multiorgan involvement [9]. Overall, the incidence of major complications, during stem cell mobilization and collection is approximately $15 \%[19,20]$. To minimize the risk of toxicity, it is recommended that only granulocyte colony-stimulating factor (G-CSF) be used for mobilization, since its use in combination with cyclophosphamide is associated with increased cardiac morbidity, a significantly higher number of aphereses required for CD34 harvesting, greater need of hospitalization, and increased toxicity, although cyclophosphamide may have a role in stem cell mobilization in patients with $\mathrm{AL}$ amyloidosis and multiple myeloma. The recommended dose of GCSF is $10-16 \mu \mathrm{g} / \mathrm{kg} /$ day, either as a single dose or in two divided doses, 3 days prior to stem cell collection. The recommended optimal dose of CD34+ cells in AL patients is at least $5 \times 10^{6} \mathrm{CD} 34+$ cells $/ \mathrm{kg}$ [21]. Plerixafor, CXCR4 receptor antagonist, as a stem cell mobilization regimen along with an abbreviated dose of G-CSF can be beneficial in patients with fluid overload to reduce the dose of G-CSF and reduce the risk of capillary leak syndrome and also reduce the number of leukapheresis session needed for optimal stem cell collection yield [22, 23]. 


\section{Conditioning Regimens prior to SCT}

Preparative regimen is usually intravenous melphalan alone, using a risk-adapted dose modification schema. The dose of melphalan can vary from 100 to 200 $\mathrm{mg} / \mathrm{m}^{2}$ based on the risk-adapted approach, described by Comenzo and Gertz [24] to reduce treatment-related morbidity and mortality associated with HDM/SCT. Tandem cycles of HDM have been shown to improve the proportion of patients who ultimately achieve a hematologic CR in $31 \%$ of patients, leading to an overall CR rate of $67 \%$ [25]. Additionally, tandem cycles of modified HDM at $100 \mathrm{mg} / \mathrm{m}^{2}$ given 3-6 months apart also can lead to median OS and progression-free survival of, respectively, 68 and 38 months in a multicenter trial [26]. A large series of 334 patients with AL amyloidosis treated with HDM/SCT reported a median OS of 6.1 years and a median event-free survival of 4.3 years, with a median OS reaching 13.4 years for patients who had achieved a hematologic CR. The overall hematologic response rate was $69 \%$, and TRM was $3 \%$ after 2010 [27]. A pilot study of incorporation of bortezomib with $\mathrm{HDM}$ in the treatment of $\mathrm{AL}$ amyloidosis has shown promising results with high hematologic response rates [28].

\section{Post-SCT Consolidation and Maintenance Therapy}

The use of consolidation therapy has been studied by the group at the MSKCC in clinical trials, first with thalidomide [29] and then more recently with bortezomib [30]. Thalidomide consolidation led to $42 \%$ improvement in hematologic response after HDM/SCT, although only half of the patients were able to complete all planned cycles of post-SCT consolidation. Bortezomib consolidation performed at 3 months after SCT led to $86 \%$ improvement in hematologic response in those who did not achieve a CR at 3 months after SCT; however, there was one death and three grade 3 cardiac events during consolidation therapy out of 22 patients.

Maintenance therapy after HDM/SCT has not been systematically studied in AL amyloidosis due to relatively low plasma cell burden as well as durable hematologic response without treatment and poor tolerability. A clinical trial of ixazomib as maintenance therapy post-SCT is currently ongoing and accruing (ClinicalTrials.gov identifier: NCT03618537).

\section{Hematologic Responses to HDM/SCT}

Deep and durable hematologic responses can be achieved after HDM/SCT. Our group previously reported on 647 patients with AL amyloidosis who underwent $\mathrm{HDM} / \mathrm{SCT}$ over a 22-year period, with hematologic CR in $39.2 \%$ at $6-12$ months following HDM/SCT. The CR rate was $33 \%$ by intention-to-treat [31]. Hematologic relapse occurred in $32 \%$ of patients after achievement of a $\mathrm{CR}$ at a median of 4.3 years (range 1.4-21.5). The median OS of patients after hematologic relapse is 8.5 years. Another large series from the Mayo clinic of 672 patients treated over a 20 -year period showed an overall hematologic response rates of $69-84 \%$ over the three predefined time periods [32].

\section{Clinical Responses to HDM/SCT}

The initial report of renal responses following HDM/ SCT was published in 2001. In this report, $36 \%$ of patients had a renal response at 12 months defined as a $50 \%$ reduction in 24-h urinary protein excretion in the absence of a $25 \%$ or greater reduction in creatinine clearance [33]. There was a striking difference in the renal response rate among those with a complete hematologic response (71\%) and those with persistence of the plasma cell dyscrasia (11\%). Since then, reports of improvements in quality of life [34], hepatic responses [35], and cardiac responses [36] have been published. Similar to renal response, clinical responses in other organ systems are more evident with hematologic responses and can take up from 6 to 12 months or longer to occur.

\section{Experience of $\mathrm{HDM} / \mathrm{SCT}$ in the Treatment of $\mathrm{AL}$ Amyloidosis at Other Centers}

The long-term outcome of a large number of patients with AL amyloidosis undergoing HDM/SCT has recently been reported from many centers. The Mayo clinic reported on an estimated 15-year OS of 30\%, and this was significantly prolonged for patients achieving a hematologic CR at 19.3 years compared to 5 years for those not achieving a hematologic CR [37]. Absence of heart involvement, receiving full $\mathrm{HDM}$ and achievement of hematologic CR remained independent predictors of survival following SCT in AL amyloidosis in this series. The UK National Amyloidosis Center also has recently reported on 264 patients undergoing HDM/SCT for AL amyloidosis with a 
median OS of 8.2 years and long-term survival of $33 \%$ at 20 years [38]. A large registry data from the CIBMTR from 134 centers again showed improvement in the 5-year OS in patients undergoing $\mathrm{HDM} / \mathrm{SCT}$ for $\mathrm{AL}$ amyloidosis. The authors concluded that post-SCT survival has improved drastically over the last few decades with reduction in treatment-related early mortality, and randomized trials are needed with non-SCT regimens [39].

The only randomized phase III study by the French group failed to show a survival benefit for HDM/SCT [40]. However, in this study, many of the patients randomized to the HDM/SCT arm were not actually transplanted, the toxicity on the transplant arm was excessive with early mortality of $26 \%$, and follow-up is short. Thus, the question of optimal therapy remains open, particularly as transplant techniques are refined, and non-transplant regimens are improved. However, it is clear that patients should be carefully selected for transplant, as advanced cardiac disease, hypotension, and poor performance status are poor prognostic factors for the outcome of $\mathrm{HDM} / \mathrm{SCT}$.

\section{HDM/SCT in Special Circumstances: In Cardiac Involvement}

Severity of cardiac involvement in AL amyloidosis remains a predictor for complications and morbidity/mortality during SCT process. However, emphasis on the importance of careful patient selection, risk-adapted strategies, experience of the transplant center and team cannot be undermined. Earlier report from our center on 53 patients with cardiac AL amyloidosis undergoing HDM/ SCT reported TRM of 4\% (stage III patients with TRM of $8 \%)$ and with a medina follow-up of 36 months, 3-year OS was $89 \%$ [41]. Moreover, 20 patients with advanced cardiac involvement with troponin $\mathrm{I}>0.1 \mathrm{ng} / \mathrm{mL}$ underwent HDM/SCT and with a median follow-up of 2.7 years, median OS was not reached [42].

\section{HDM/SCT in Special Circumstances: Following Heart Transplantation}

In patients with end-stage heart failure, heart transplantation may be required as a life-saving procedure. Because of the high likelihood of amyloid recurrence in the transplanted organ, as well as progression in other organs, heart transplantation must be followed by anti-plasma cell therapy. Although the long-term survival is statistically inferior to that of patients with non-amyloid heart disease, the actuarial 5-year survival appears to be $65 \%$ with treatment for the underlying plasma cell dyscrasia. Thus, carefully selected patients, without other significant organ involvement, can benefit from heart transplantation followed by aggressive anti-plasma cell treatment [43, 44].

\section{HDM/SCT in Special Circumstances: In Patients with Renal Disease}

Predisposing factors for the development of acute kidney injury (AKI) during SCT was studied in a retrospective study. Approximately $21 \%$ of the patients developed AKI, 5\% required dialysis peri-SCT period, and $46 \%$ had complete recovery of renal function. Risk factors for AKI included higher urine protein excretion, lower creatinine clearance at baseline, cardiac involvement, higher melphalan dose, and development of bacteremia during SCT [45]. HDM/SCT can also be safely and cautiously performed in patients with end-stage renal disease on dialysis and inducing durable hematologic responses then can make patients eligible for renal transplantation [46].

\section{Current Recommendations and Future Directions}

Our data and that from other centers indicate that, despite multisystem organ dysfunction, selected patients with AL amyloidosis can tolerate HDM and autologous SCT. Moreover, high-dose chemotherapy can induce complete hematologic responses in a substantial proportion of patients who complete treatment. Furthermore, complete hematologic responses in AL amyloidosis are associated with reversal of amyloid-related organ dysfunction and may lead to prolonged survival in this disease.

While patient selection remains important in achieving an acceptable outcome, we also believe it is in part attributable to the multidisciplinary approach to patient management. A team of subspecialists who are familiar with the manifestations and treatment of amyloidosis, in our program, evaluate each patient. These subspecialists remain available to the transplant physicians throughout therapy, and the amyloid clinical team meets regularly to review each patient's progress during treatment. We encourage other transplant centers undertaking treatment of these complicated patients to adopt a similar multidisciplinary management approach. 


\section{Conclusions}

Promising treatments, besides HDM/SCT, are available for patients with $\mathrm{AL}$ amyloidosis. Although these treatment regimens are not discussed here in this review, the availability of new regimens for treatment of AL amyloidosis may provide additional options for patients who are not eligible for HDM/SCT in the future. Timing and sequencing of regimens containing these agents, and comparison to or combination with HDM/SCT, will be determined in future trials.

\section{Acknowledgements}

I gratefully acknowledge my colleagues in the Amyloidosis Center, Cancer and Hematology Research Program Office, and the staff of the Solomont Center for Cancer and Blood Disorders at Boston Medical Center who assisted with the multidisciplinary evaluation and treatment of the patients.

\section{Disclosure Statement}

The author has no competing financial interests to declare.

\section{References}

1 Merlini G, Dispenzieri A, Sanchorawala V, Schönland SO, Palladini G, Hawkins PN, et al. Systemic immunoglobulin light chain amyloidosis. Nat Rev Dis Primers. 2018 Oct;4(1): 38.

2 Merlini G, Bellotti V. Molecular mechanisms of amyloidosis. N Engl J Med. 2003 Aug; 349(6):583-96.

3 Palladini G, Dispenzieri A, Gertz MA, Kumar S, Wechalekar A, Hawkins PN, et al. New criteria for response to treatment in immunoglobulin light chain amyloidosis based on free light chain measurement and cardiac biomarkers: impact on survival outcomes. J Clin Oncol. 2012 Dec;30(36):4541-9.

4 Palladini G, Hegenbart U, Milani P, Kimmich C, Foli A, Ho AD, et al. A staging system for renal outcome and early markers of renal response to chemotherapy in AL amyloidosis. Blood. 2014 Oct;124(15):2325-32.

5 Kaufman GP, Dispenzieri A, Gertz MA, Lacy MQ, Buadi FK, Hayman SR, et al. Kinetics of organ response and survival following normalization of the serum free light chain ratio in AL amyloidosis. Am J Hematol. 2015 Mar; 90(3):181-6.

6 Attal M, Harousseau JL, Stoppa AM, Sotto JJ, Fuzibet JG, Rossi JF, et al. A prospective, randomized trial of autologous bone marrow transplantation and chemotherapy in multiple myeloma. Intergroupe Français du Myélome. N Engl J Med. 1996 Jul;335(2):91-7.

7 Child JA, Morgan GJ, Davies FE, Owen RG, Bell SE, Hawkins K, et al.; Medical Research Council Adult Leukaemia Working Party. High-dose chemotherapy with hematopoietic stem-cell rescue for multiple myeloma. $\mathrm{N}$ Engl J Med. 2003 May;348(19):1875-83.

8 Comenzo RL, Vosburgh E, Simms RW, Bergethon P, Sarnacki D, Finn K, et al. Dose-intensive melphalan with blood stem cell support for the treatment of AL amyloidosis: oneyear follow-up in five patients. Blood. 1996 Oct;88(7):2801-6.

9 Skinner M, Sanchorawala V, Seldin DC, Dember LM, Falk RH, Berk JL, et al. Highdose melphalan and autologous stem-cell transplantation in patients with $\mathrm{AL}$ amyloidosis: an 8-year study. Ann Intern Med. 2004 Jan;140(2):85-93.

10 Cibeira MT, Sanchorawala V, Seldin DC, Quillen K, Berk JL, Dember LM, et al. Outcome of AL amyloidosis after high-dose melphalan and autologous stem cell transplantation: long-term results in a series of $421 \mathrm{pa}-$ tients. Blood. 2011 Oct;118(16):4346-52.

11 Sanchorawala V, Sun F, Quillen K, Sloan JM, Berk JL, Seldin DC. Long-term outcome of patients with AL amyloidosis treated with high-dose melphalan and stem cell transplantation: 20-year experience. Blood. 2015 Nov; 126(20):2345-7.

12 Gertz MA, Lacy MQ, Dispenzieri A, Kumar SK, Dingli D, Leung N, et al. Refinement in patient selection to reduce treatment-related mortality from autologous stem cell transplantation in amyloidosis. Bone Marrow Transplant. 2013 Apr;48(4):557-61.

13 Sanchorawala V, Wright DG, Seldin DC, Falk RH, Finn KT, Dember LM, et al. High-dose intravenous melphalan and autologous stem cell transplantation as initial therapy or following two cycles of oral chemotherapy for the treatment of $\mathrm{AL}$ amyloidosis: results of a prospective randomized trial. Bone Marrow Transplant. $2004 \mathrm{Feb} ; 33(4): 381-8$.

14 Sanchorawala V, Brauneis D, Shelton AC, Lo S, Sun F, Sloan JM, et al. Induction Therapy with Bortezomib Followed by BortezomibHigh Dose Melphalan and Stem Cell Transplantation for Light Chain Amyloidosis: Results of a Prospective Clinical Trial. Biol Blood Marrow Transplant. 2015 Aug;21(8): 1445-51.

15 Huang X, Wang Q, Chen W, Zeng C, Chen Z, Gong D, et al. Induction therapy with bortezomib and dexamethasone followed by autologous stem cell transplantation versus autologous stem cell transplantation alone in the treatment of renal AL amyloidosis: a randomized controlled trial. BMC Med. 2014 Jan; 12(1):2.

16 Minnema MC, Nasserinejad K, Hazenberg B, Hegenbart U, Vlummens P, Ypma PF, et al.
Bortezomib-based induction followed by stem cell transplantation in light chain amyloidosis: results of the multicenter HOVON 104 trial. Haematologica. 2019 Nov;104(11):2274-82.

17 Hwa YL, Kumar SK, Gertz MA, Lacy MQ, Buadi FK, Kourelis TV, et al. Induction therapy pre-autologous stem cell transplantation in immunoglobulin light chain amyloidosis: a retrospective evaluation. Am J Hematol. 2016 Oct;91(10):984-8.

18 Dittus C, Uwumugambi N, Sun F, Sloan JM, Sanchorawala V. The Effect of Bone Marrow Plasma Cell Burden on Survival in Patients with Light Chain Amyloidosis Undergoing High-Dose Melphalan and Autologous Stem Cell Transplantation. Biol Blood Marrow Transplant. 2016 Sep;22(9):1729-32.

19 Yeh JC, Shank BR, Milton DR, Qazilbash MH Adverse Prognostic Factors for Morbidity and Mortality During Peripheral Blood Stem Cell Mobilization in Patients with Light Chain Amyloidosis. Biol Blood Marrow Transplant. 2018 Apr;24(4):815-9.

20 Bashir Q, Langford LA, Parmar S, Champlin RE, Qazilbash MH. Primary systemic amyloid light chain amyloidosis decompensating after filgrastim-induced mobilization and stemcell collection. J Clin Oncol. 2011 Feb; 29(4):e79-80.

21 Oran B, Malek K, Sanchorawala V, Wright DG, Quillen K, Finn KT, et al. Predictive factors for hematopoietic engraftment after autologous peripheral blood stem cell transplantation for AL amyloidosis. Bone Marrow Transplant. 2005 Mar;35(6):567-75.

22 Lee SY, Sanchorawala V, Seldin DC, Mark Sloan J, Andrea N, Quillen K. Plerixafor-augmented peripheral blood stem cell mobilization in AL amyloidosis with cardiac involvement: a case series. Amyloid. 2014 Sep;21(3):149-53.

23 Dhakal B, Strouse C, D'Souza A, Arce-Lara C, Esselman J, Eastwood D, et al. Plerixafor and abbreviated-course granulocyte colony-stimulating factor for mobilizing hematopoietic progenitor cells in light chain amyloidosis. Biol Blood Marrow Transplant. 2014 Dec; 20(12):1926-31. 
24 Comenzo RL, Gertz MA. Autologous stem cell transplantation for primary systemic amyloidosis. Blood. 2002 Jun;99(12):4276-82.

25 Sanchorawala V, Wright DG, Quillen K, Finn KT, Dember LM, Berk JL, et al. Tandem cycles of high-dose melphalan and autologous stem cell transplantation increases the response rate in AL amyloidosis. Bone Marrow Transplant. 2007 Sep;40(6):557-62.

26 Sanchorawala V, Hoering A, Seldin DC, Finn KT, Fennessey SA, Sexton R, et al. Modified high-dose melphalan and autologous SCT for AL amyloidosis or high-risk myeloma: analysis of SWOG trial S0115. Bone Marrow Transplant. 2013 Nov;48(12):1537-42.

27 Nguyen VP, Landau H, Quillen K, Brauneis D, Shelton AC, Mendelson L, et al. Modified high-dose melphalan and autologous stem cell transplantation for AL amyloidosis: experience in 334 patients. Biol Blood Marrow Transplant. 2018 Sep;24(9):1823-7.

28 Sanchorawala V, Quillen K, Sloan JM, Andrea NT, Seldin DC. Bortezomib and high-dose melphalan conditioning for stem cell transplantation for AL amyloidosis: a pilot study. Haematologica. 2011 Dec;96(12):1890-2.

29 Cohen AD, Zhou P, Chou J, Teruya-Feldstein J, Reich L, Hassoun H, et al. Risk-adapted autologous stem cell transplantation with adjuvant dexamethasone $+/$ - thalidomide for systemic light-chain amyloidosis: results of a phase II trial. Br J Haematol. 2007 Oct; 139(2): 224-33.

30 Landau $\mathrm{H}$, Hassoun $\mathrm{H}$, Rosenzweig MA, Maurer M, Liu J, Flombaum C, et al. Bortezomib and dexamethasone consolidation following risk-adapted melphalan and stem cell transplantation for patients with newly diagnosed light-chain amyloidosis. Leukemia. 2013 Apr;27(4):823-8.

31 Browning S, Quillen K, Sloan JM, Doros G, Sarosiek S, Sanchorawala V. Hematologic relapse in $\mathrm{AL}$ amyloidosis after high-dose melphalan and stem cell transplantation. Blood. 2017 14;130(11):1383-6.
32 Sidiqi MH, Aljama MA, Buadi FK, Warsame RM, Lacy MQ, Dispenzieri A, et al. Stem Cell Transplantation for Light Chain Amyloidosis: Decreased Early Mortality Over Time. J Clin Oncol. 2018 May;36(13):1323-9.

33 Dember LM, Sanchorawala V, Seldin DC, Wright DG, LaValley M, Berk JL, et al. Effect of dose-intensive intravenous melphalan and autologous blood stem-cell transplantation on al amyloidosis-associated renal disease. Ann Intern Med. 2001 May;134(9 Pt 1):74653.

34 Seldin DC, Anderson JJ, Sanchorawala V, Malek K, Wright DG, Quillen K, et al. Improvement in quality of life of patients with AL amyloidosis treated with high-dose melphalan and autologous stem cell transplantation. Blood. 2004 Sep;104(6):1888-93.

35 Girnius S, Seldin DC, Skinner M, Finn KT, Quillen K, Doros G, et al. Hepatic response after high-dose melphalan and stem cell transplantation in patients with AL amyloidosis associated liver disease. Haematologica. 2009 Jul;94(7):1029-32.

36 Salinaro F, Meier-Ewert HK, Miller EJ, Pandey S, Sanchorawala V, Berk JL, et al. Longitudinal systolic strain, cardiac function improvement, and survival following treatment of light-chain (AL) cardiac amyloidosis. Eur Heart J Cardiovasc Imaging. 2017 Sep;18(9): 1057-64.

37 Sidana S, Sidiqi MH, Dispenzieri A, Buadi FK, Lacy MQ, Muchtar E, et al. Fifteen Year Overall Survival Rates after Autologous Stem Cell Transplantation for AL Amyloidosis. Am J Hematol. 2019 Jun;94(9):1020-6.

38 Sharpley FA, Petrie A, Mahmood S, Sachchithanantham S, Lachmann HJ, Gillmore JD, et al. A 24-year experience of autologous stem cell transplantation for light chain amyloidosis patients in the United Kingdom. Br J Haematol. 2019 Dec;187(5):642-52.

39 D'Souza A, Dispenzieri A, Wirk B, Zhang MJ, Huang J, Gertz MA, et al. Improved Outcomes After Autologous Hematopoietic Cell Transplantation for Light Chain Amyloidosis: A Center for International Blood and Marrow Transplant Research Study. J Clin Oncol. 2015 Nov;33(32):3741-9.
40 Jaccard A, Moreau P, Leblond V, Leleu X, Benboubker L, Hermine O, et al.; Myélome Autogreffe (MAG) and Intergroupe Francophone du Myélome (IFM) Intergroup. Highdose melphalan versus melphalan plus dexamethasone for AL amyloidosis. N Engl J Med. 2007 Sep;357(11):1083-93.

41 Girnius S, Seldin DC, Meier-Ewert HK, Sloan JM, Quillen K, Ruberg FL, et al. Safety and efficacy of high-dose melphalan and auto-SCT in patients with $\mathrm{AL}$ amyloidosis and cardiac involvement. Bone Marrow Transplant. 2014 Mar;49(3):434-9.

42 White PS, Phull P, Brauneis D, Sloan JM, Quillen K, Sarosiek S, et al. High-dose melphalan and stem cell transplantation in $\mathrm{AL}$ amyloidosis with elevated cardiac biomarkers. Bone Marrow Transplant. 2018 Dec; 53(12):1593-5.

43 Grogan M, Gertz M, McCurdy A, Roeker L, Kyle R, Kushwaha S, et al. Long term outcomes of cardiac transplant for immunoglobulin light chain amyloidosis: The Mayo Clinic experience. World J Transplant. 2016 Jun; 6(2):380-8.

44 Dey BR, Chung SS, Spitzer TR, Zheng H, Macgillivray TE, Seldin DC, et al. Cardiac transplantation followed by dose-intensive melphalan and autologous stem-cell transplantation for light chain amyloidosis and heart failure. Transplantation. 2010 Oct; 90(8):905-11.

45 Fadia A, Casserly LF, Sanchorawala V, Seldin DC, Wright DG, Skinner M, et al. Incidence and outcome of acute renal failure complicating autologous stem cell transplantation for AL amyloidosis. Kidney Int. 2003 May;63(5): 1868-73.

46 Batalini F, Econimo L, Quillen K, Sloan JM Sarosiek S, Brauneis D, et al. High-Dose Melphalan and Stem Cell Transplantation in $\mathrm{Pa}$ tients on Dialysis Due to Immunoglobulin Light-Chain Amyloidosis and Monoclonal Immunoglobulin Deposition Disease. Biol Blood Marrow Transplant. 2018 Jan;24(1): $127-32$. 